\title{
Tooth wear and microwear of theropods from the Late Maastrichtian Marília Formation (Bauru Group), Minas Gerais State, Brazil
}

\author{
Carlos Roberto A. Candeiro*1, Philip J. Currie ${ }^{2}$, Caio L. Candeiro ${ }^{3}$ and \\ Lílian P. Bergqvist ${ }^{4}$
}

${ }^{1}$ Laboratório de Paleontologia, Curso de Geologia, Campus Aparecida de Goiânia, Universidade Federal de Goiás, Aparecida de Goiânia 74968-755, Goiás State, Brazil.

Email: candeiro@ufg.br

${ }^{2}$ Department of Biological Sciences, University of Alberta, Edmonton, Alberta T6G 2E9, Canada.

Email: philip.currie@ualberta.ca

${ }^{3}$ Faculdade de Odontologia, Universidade Federal de Uberlândia. Av. Pará, s/nº - Bloco 2G - Sala 2G07, Jardim Umuarama, São Paolo, Brazil

${ }^{4}$ Laboratório de Macrofósseis, Departamento de Geologia, Universidade Federal do Rio de Janeiro. Av. Athos da Silveira Ramos, 274, Ilha do Fundão, Rio de Janeiro, Brazil

* Corresponding author

\begin{abstract}
Little is known about the tooth wear of South American theropod dinosaurs. This paper describes wear facets in Abelisauridae, Carcharodontosauridae and some indeterminate theropods teeth, from the Marília Formation. Four types of wear facets are proposed: verticallyoriented attritional striations; perpendicular attritional surfaces; oval wear facets; and apical grooves. All these worn surfaces were produced by dental occlusion, except the apical grooves, which are produced by the contact between predator teeth and the prey bone during predator-prey interaction. More detailed biomechanical and hardness testing of teeth and bone may further elucidate the pattern of tooth wear in theropods.
\end{abstract}

KEY WORDS: Cretaceous, dinosaurs, facets, macrowear, theropod teeth.

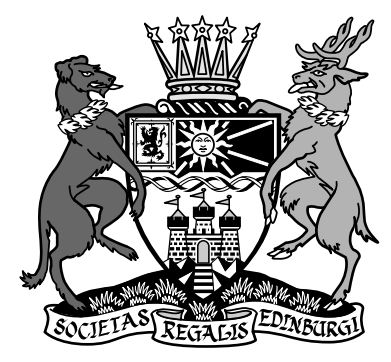

A general hypothesis regarding most theropod dinosaurs is that they were active predators or scavengers (Paul 1988). Fossil evidence of this behavior is well known in the fossil record of Laurasia, but not in Gondwana (Fastovsky et al. 2004). The scarce information on the diet of South American theropods is due to the lack of discoveries of worn teeth, or even of bones with tooth marks, only a few of which have yet been found. In Brazil, theropod teeth from the Marília Formation of the Sítio Paleontológico de Peirópolis comprise one of the largest and most diverse fossil tooth collections in South America.

Little is known about the feeding biomechanics of theropod dinosaurs, especially the role of teeth on bite force and the estimated pressure produced by them (bite force/tooth contact area). As observed in crocodiles by Erickson et al. (2012a), these biomechanical aspects might be related to variations in rostral and dental morphologies, body size, feeding ecology or other evolutionary variations. The current knowledge about tooth pressure (the forces inflicted in the act of biting the prey and on tooth-on-tooth contact) of dinosaurs is still scarce, and previous research on this subject has concentrated on ornithischian dinosaurs, mammals, sharks and other fish (e.g., Lee et al. 2011; Mallon \& Anderson 2014; Erickson et al. 2014; Rowe et al. 2014).

Some studies described striated surfaces on dinosaur teeth and suggested they are directly related to mastication (Weishampel
1984; Fiorillo 1991, 1995, 1997, 1998; Weishampel \& Norman 1989; Upchurch \& Barrett 2000; Barrett 2001; Rybczynski \& Vickaryous 2001; Sankey et al. 2002; D'Amore 2009; Erickson et al. 2012b, 2015; Sereno 2012; Mallon \& Anderson 2014). Most of these studies analysed herbivorous ornithischians and sauropods, by comparing and contrasting the feeding habits of theropods, varanids, crocodyliforms and mammals. By observing the feeding mechanism of mammals, Weishampel (1984) noticed that herbivorous hadrosaurid dinosaurs show similar parallel striations on the enamel of opposing tooth facets, which suggests that this was probably related to the direction of tooth occlusion during mastication.

Farlow \& Brinkman (1994) and Schubert \& Ungar (2005) pointed out that tyrannosaurids have almost the same wear patterns as found in other theropod teeth, which suggests occlusion of opposing teeth. This partially corroborates Williamson $\&$ Brusatte (2014), although they also indicated that the parallel striations on the lateral teeth of tyrannosaurids were produced during predation by contact between the tyrannosaurid teeth and the bones of the prey.

Predation marks on bones, produced by theropods, are another source of information on their feeding behaviour (D'Amore 2009). Carnivorous dinosaurs had a varied feeding behaviour, and their tooth marks have been reported on other dinosaur and pterosaur bones (Currie \& Jacobsen 1995; Erickson et al. 1996; Erickson \& Olson 1996; D’Amore 2009). Schubert \& 
Ungar (2005) observed that the wear surfaces of tyrannosaurid teeth have specific shapes and orientations that can be classified as spalled surfaces caused by antemortem enamel flaking, and attritional facets produced by tooth-to-tooth contact during feeding.

According to Jacobsen (1998), patterns of bone marks produced by some crocodilian and mammalian carnivores are comparable to the ones left by theropod dinosaurs. Studies of tooth marks on dinosaur bones from North America have been used to identify the feeding behaviour of theropods at both a family and a generic level (Holz et al. 1998; Jacobsen \& Bromley 2009).

The shape of the denticles, and the distance between them in the jaws, provides clues for the identification of tooth marks. In Laurasian theropods (dromaeosaurids and tyrannosaurids), parallel and serration marks have been identified (Chandler 1990; Abler 1992; Currie \& Jacobsen 1995; Brochu 2003; D'Amore 2009).

Research on tooth wear surfaces is potentially important to a palaeoecological study of Brazilian Late Cretaceous dinosaurs. The present study aims to analyse the tooth macrowear and microwear of theropods from Sítio Paleontológico de Peirópolis and correlate it with feeding habits.

\section{Material and methods}

All the specimens analysed are from the Marilia Formation (Maastrichtian) of Peirópolis, Uberaba City, Minas Gerais State, Brazil (Fig. 1), a fossil site where many theropod bones have been found. The known theropod taxa include abelisaurids, carcharodontosaurids and several taxa of indeterminate theropods (Candeiro et al. 2012).

The studied specimens include teeth of Abelisauridae (CPP 020, 136, 150, 205, 242, 243, 271, 452/1), Carcharodontosauridae (CPP 124, 129a, 152, 199, 376, 447, 449) and unidentified theropods (CPP 135, 154, 161/1, 198, 371, 377, 446, 451/1, 476, 478).

The macrowear surfaces were initially analysed using a hand lens, and light microscopy, to elucidate details such as the nature of the enamel-dentine transition or the presence of secondary enamel ridges. The microwear analysis was undertaken with the support of a scanning electron microscope.

The taxonomic classification of the analysed fossil assemblage follows the identifications proposed by Candeiro et al. (2012). The classification of the pattern of tooth wear follows the proposals of Molnar (1998), Schubert \& Ungar (2005) and Hendrickx et al. (2015).

Institutional abbreviations. CPP, Centro de Pesquisas Paleontológicas Llewellyn Ivor Price, Peirópolis, Uberaba, Minas Gerais State, Brazil.

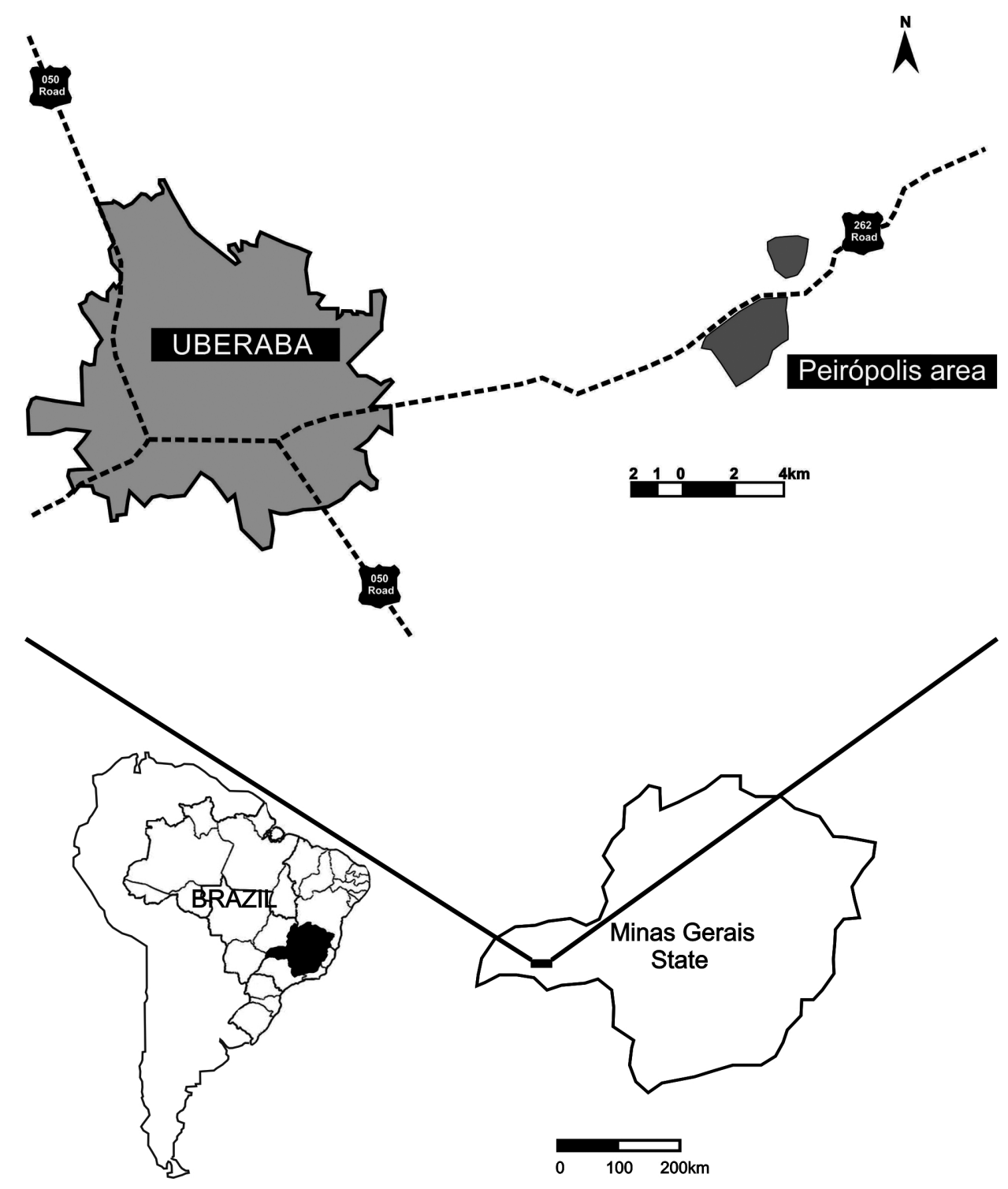

Figure 1 Location map of Peirópolis site, Minas Gerais State, Brazil. 


\section{Results}

\subsection{Microwear - attritional striations}

Specimens: CPP 129a, 129b (Abelisauridae); CPP 199 (Carcharodontosauridae).

The enamel on the labial and lingual surfaces of CPP 129a, $129 \mathrm{~b}$ and 199 is characterised by shallow depressions on the apices. The wear striations are vertically oriented, deeper along the central portion of each groove, and have irregular edges. (Fig. 2). The main microwear features present on the tooth surface are narrow striations, occasionally oriented perpendicular to the deeper striations (Fig. 2A), in a similar way as in Daspletosaurus torosus (see Schubert \& Ungar 2005). These features suggest two types of interactions caused by dental enamel friction (Fig. 2B, C): the deeper wear surfaces were made in an occlusal direction; whereas the perpendicular striations were possibly produced by contact with prey bone (see Schubert \& Ungar 2005)

\subsection{Microwear - oval shape}

Specimens: CPP 124, 131, 132, 135, 136, 152, 154, 161/1, 198, 199, 205, 242, 243, 271, 371, 377, 446, 447, 449, 451/1, 452/1, $463,476,478$
These teeth show oval apical wear, clearly exposing the enamel dentine joint (EDJ). These oval surfaces with shallow striations are present on both sides of the teeth, but they are smoother on concave surfaces (Fig. 3). The striations are predominantly oriented anteroposteriorly. The enamel surfaces are covered by numerous shallow scratches that are mostly oriented perpendicular to tooth borders. This is true for both sides of the teeth, but the scratches are more common on the labial side.

\subsection{Macrowear - abrupt fracture}

Specimens: CPP 020, 129a.

The macrowear patterns found in some theropod dinosaurs are very conspicuous in these specimens. The apical ends of them are abruptly fractured and it is especially evident on the labial surfaces (Fig. 4). The tooth borders are slightly abraded, but do not reach the EDJ. Attritional striations are horizontally oriented, and in some cases they extend to the posterior edge of the tip of the crown (Fig. 4B). The abrasion of the enamel of specimen CPP 129a (Fig. 4B) is very conspicuous, because both lingual and labial surfaces are thinner and irregular, exposing the dentine. It is possible that some of the wear on CPP 129a was caused by acidic liquids of the gastrointestinal tract.

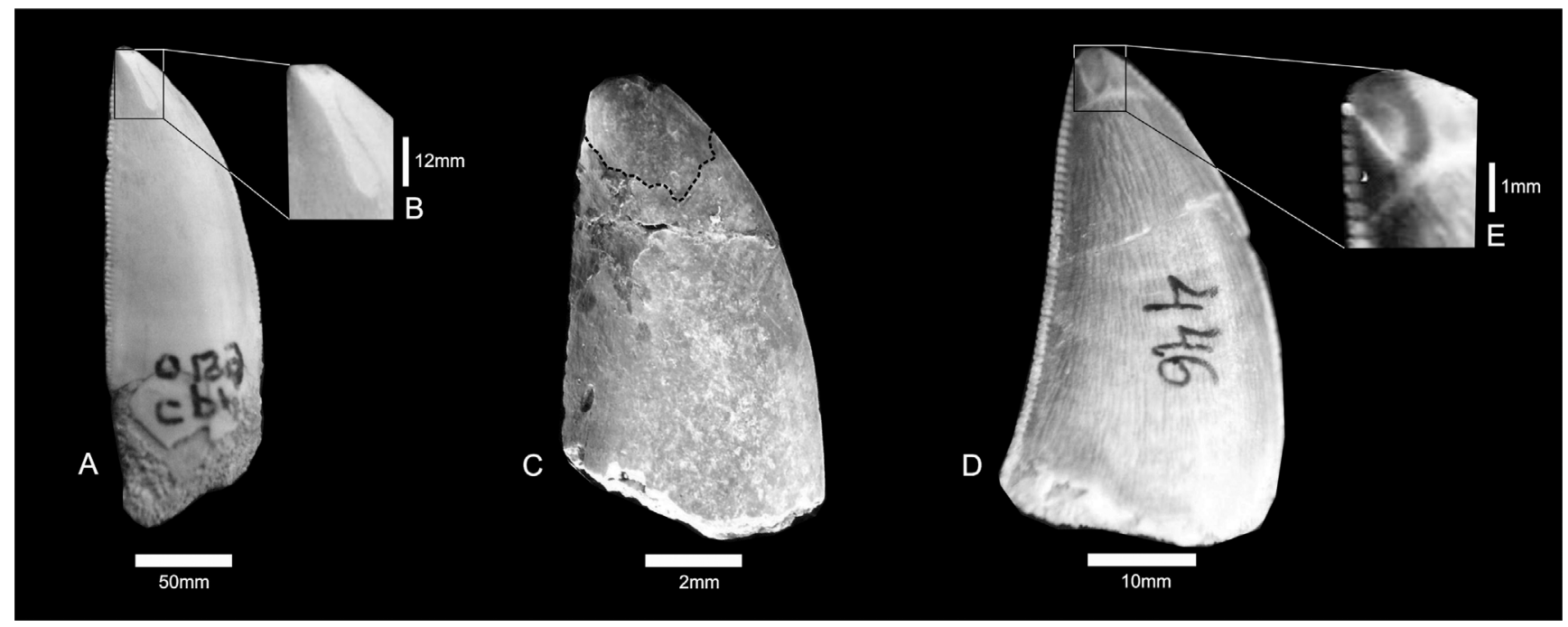

Figure 2 (A-B) Carcharodontosauridae indet., CPP 199; close-up of tooth surface showing vertical striations (C) Abelisauridae indet., CPP 129b. (D-E) Theropoda indet., CPP 446; close-up of apical surface showing broad

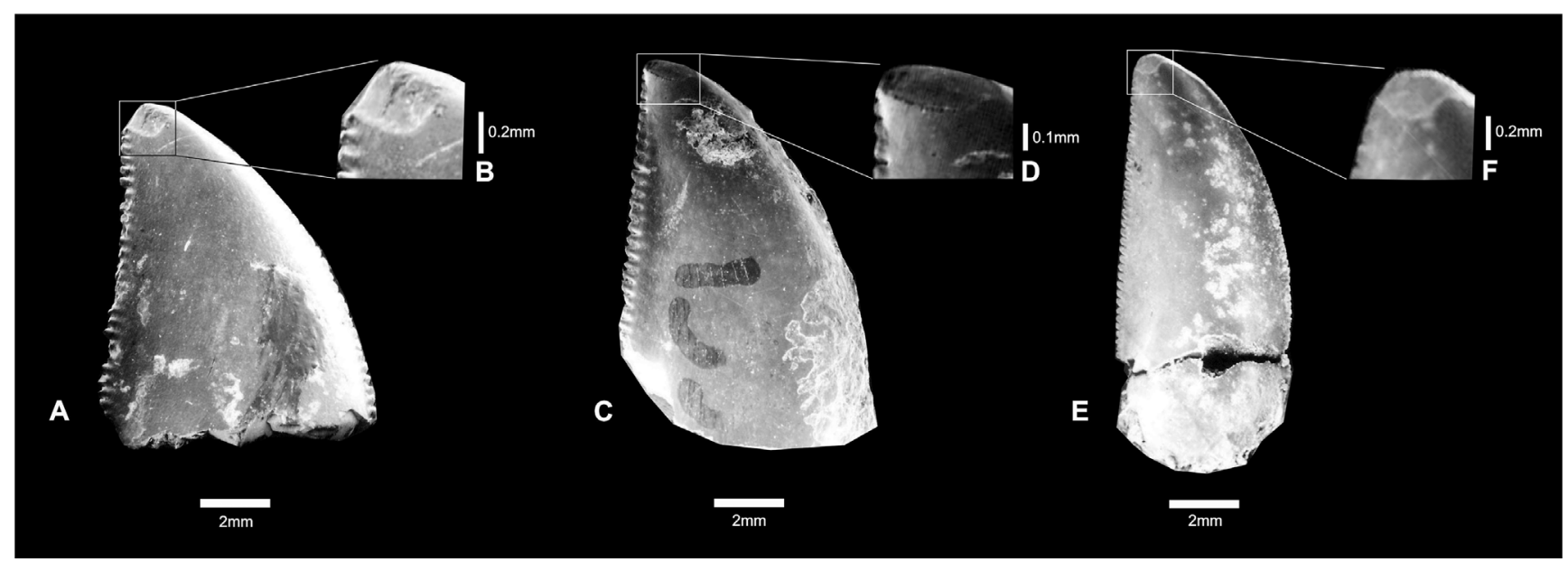

Figure 3 (A-B) Theropoda indet., CPP 132; close-up showing oval wear surface. (C-D) Carcharodontosauridae indet., CPP 133; close-up showing oval wear surface. (E-F) Abelisauridae indet., CPP 154; close-up showing oval wear surface. 


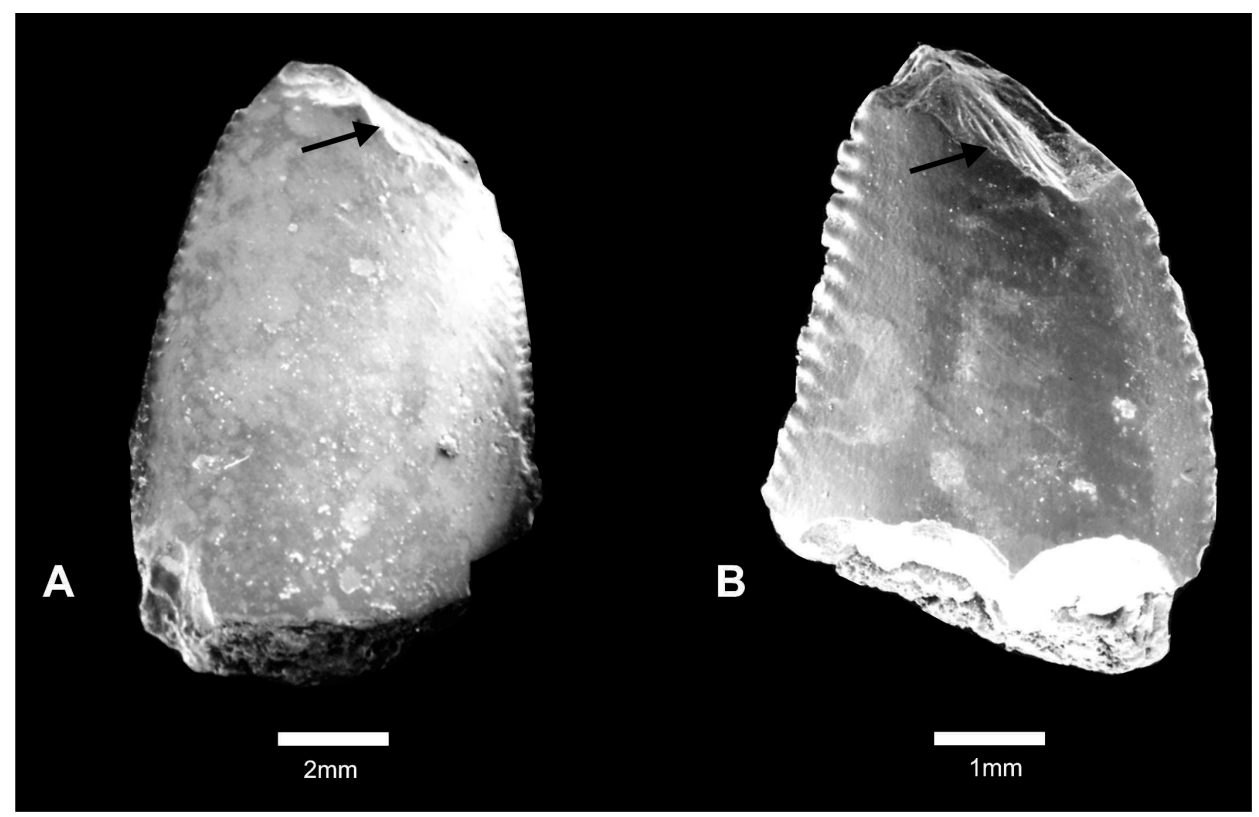

Figure 4 Macrowear abrupt fractures: (A) Abelisauridae indet., CPP 020; (B) Carcharodontosauridae indet., CPP 129a. Arrows indicated broken surface.

\section{Discussion and conclusions}

The tooth surface of theropods was continuously worn out throughout its use. Tooth wear is represented by vertical abrasion caused by friction, and some of these wear facets have perpendicular striations (Fig. 2A). These two types of striation were produced by different jaw movements.

On both lingual and labial faces, attritional striations are mainly observed on the apical region of the teeth. The striations get narrower towards the apex. Wear striations have been used to indicate the orientation of the force of dental occlusion, as one tooth slides over another (Abler 1992; Schubert \& Ungar 2005; D'Amore 2009). Attritional striations are more prominent at the tooth tips, and become more attenuated towards the roots. Candeiro (2002) asserted that the wear surfaces tend to be oval near the tips, but subsequently become elongated. If this is correct, the initial oval wear facets on theropod teeth must have been produced by tooth contact with bone surface during feeding, because attritional striations only occur during occlusion (sensu Abler 1992; Schubert \& Ungar 2005; D'Amore 2009).

The macrowear and microwear patterns on the theropod teeth from the Late Maastrichtian of the Marilia Formation have different extents and shapes. First, the observed shapes (oval shape and abrupt fracture) could have been interpreted as a result of either tooth-to-tooth contact (Schubert \& Ungar 2005; D'Amore 2009) or tooth-to-bone contact. In some cases, this type of occlusion may expose the dentine. Some teeth from the Marília Formation show this type of oval wear. These teeth are usually not affected on their anterior and posterior carinae, which still possess small denticles.

A conspicuous type of wear observed in specimens CPP $129 \mathrm{a}, 129 \mathrm{~b}$ and 199 is a characteristic elongated groove that starts at the tooth apex. It suggests that penetration into hard surfaces spalled off enamel flakes from the tooth. The grooves are present on both labial and lingual faces of the enamel and expose the dentine. This evidence confirms the direction of the bite and shows greater force was used during the bonepenetrating bite.
The attritional striations, the oval wear facets and the apical grooves observed in the teeth analysed suggest that theropods from the Upper Maastrichtian Marília Formation had the same range of feeding habits as theropods from other parts of the world. Abelisaurids and carcharodontosaurids are medium-to-large sized, top predators and/or scavengers that fed especially on large prey. This behaviour probably produced the range of tooth wear observed in these dinosaurs. No published studies have yet analysed the hardness and resistance of the bones of herbivorous dinosaurs from the Marilia Formation. A study of this nature would contribute to the understanding of how these abrasions are formed.

The oval shape, attritional striations and abrupt tooth fractures are tooth wear patterns comparable to those seen on the occlusal facets of other reptiles. It shows a tooth-on-tooth contact between opposing teeth that occurs repeatedly in one direction, in a scissor-like occlusion pattern (sensu Schubert \& Ungar 2005). The different patterns of enamel wear surfaces indicate different feeding mechanisms amongst the theropod dinosaurs of the Sítio Paleontológico de Peirópolis. The patterns of wear surfaces, such as their attritional striations and oval shapes, were probably formed by their effective cutting teeth (like a scissor with serrated blades), which was similarly observed by Schubert \& Ungar (2005) on tyrannosaurid teeth. This type of occlusion is probably related to higher bite forces that produce striations on the lingual and labial surfaces, extending to the crown surfaces of the teeth - a feature similar to those observed by Molnar (1998). The seemingly powerful bite force of these theropods could have produced the abrupt fractures present on the specimens described here. Thus, the apexes of some teeth were probably susceptible to breaking during the powerful friction caused by tooth occlusion. Nevertheless, such inferences regarding their diet are somewhat speculative.

Future studies regarding theropod teeth should include biomechanical tests to analyse the hardness of enamel and dentine, as well as the degree of resistance present in the bones of potential prey species from the Marília Formation of the Sítio Paleontológico de Peirópolis. 


\section{Acknowledgments}

We are much indebted to Elsa Panciroli (University of Edinburgh) and Paulo Victor Oliveira (Universidade Federal do Rio de Janeiro), for valuable comments on the manuscript. This contribution was partially supported by the Conselho Nacional de Desenvolvimento Científico e Tecnológico (CNPq) $\mathrm{RC}$ and LB are also grateful to CNPq for the Produtividade em Pesquisa fellowship.

\section{References}

Abler, W. L. 1992. The serrated teeth of tyrannosaurid dinosaurs, and biting structures in other animals. Paleobiology 18, 161-83.

Barrett, P. M. 2001. Tooth wear and possible jaw action of Scelidosaurus harrisonii Owen and a review of feeding mechanisms in other thyreophoran dinosaurs. In Carpenter, K. (ed.) The Armored Dinosaurs, 25-52. Bloomington: Indiana University Press. 512 pp.

Brochu, C. A. 2003. Osteology of Tyrannosaurus rex: insight from a nearly complete skeleton and high resolution computed tomographic analysis of the skull. Society of Vertebrate Paleontology Memoir 7, 1-138.

Candeiro, C. R. A. 2002. Dentes de Theropoda da Formação Marília (Santoniano-Maastrichtiano), Bacia Bauru, Região de Peirópolis, Uberaba, Minas Gerais, Brasil. MSc Thesis, Programa de PósGraduação em Geologia, Universidade Federal do Rio de Janeiro. $136 \mathrm{pp}$.

Candeiro, C. R., Currie, P. J. \& Bergqvist, L. P. 2012. Theropod teeth from the Marília Formation (late Maastrichtian) at the paleontological site of Peirópolis in Minas Gerais State, Brazil. Revista Brasileira de Geociências 42, 323-30.

Chandler, C. L. 1990. Taxonomic and functional significance of serrated tooth morphology in theropod dinosaurs. Master's Thesis. Yale University, USA. 273pp.

Currie, P. J. \& Jacobsen, A. R. 1995. An azhdarchid pterosaur eaten by a velociraptorine theropod. Canadian Journal of Earth Science 32, $922-25$.

D'Amore, D. C. 2009. A functional explanation for denticulation in theropod dinosaur teeth. The Anatomical Record 292, 1297 1314

Erickson, G. M., Van Kirk, S. D., Su, J. Levenston, M. E. Caler, W.E. \& Carter, D. R. 1996. Bite-force estimation for Tyrannosaurus rex from tooth-marked bones. Science 382, 706-08.

Erickson, G. M., Gignac, P. M., Steppan, S. J., Lappin, A, K., Vliet, K. A., Brueggen, J. D., Inouye, B. D., Kledzik, D. \& Webb, G. J. W. 2012a. Insights into the Ecology and Evolutionary Success of Crocodilians Revealed through Bite-Force and Tooth-Pressure Experimentation. PLoSONE, 7(3), e31781.

Erickson, G. M., Krick, B. A., Hamilton, M., Bourne, G. R., Norell, M. A., Lilleodden, E. \& Sawyer, W. G. 2012b. Complex dental structure and wear biomechanics in hadrosaurid dinosaurs. Science 338, $510-14$.

Erickson, G. M., Gignac, P. M., Lappin, A. K., Vliet, K. A., Brueggen, J. D. \& Webb, G. J. W. 2014. A comparative analysis of ontogenetic bite-force scaling among Crocodylia. Journal of Zoology 292, 48-55.

Erickson, G. M., Sidebottom, M. A., Kay, D. I., Turner, K. T., Ip, N., Norell, M. A., Sawyer, W. G. \& Krick, B. A. 2015. Wear biomechanics in the slicing dentition of the giant horned dinosaur Triceratops. Science Advances 1, 1-7.

Erickson, G. M. \& Olson, K. H. 1996. Bite marks attributable to Tyrannosaurus rex: preliminary description and implications. Journal of Vertebrate Paleontology 16, 175-78.

Farlow, J. O. \& Brinkman, D. L. 1994. Wear surfaces on the teeth of tyrannosaurs. In Rosenberg, G. D. \& Wolberg, D. L. (eds) Dino Fest. The Paleontological Society Special Publication 7, 164-75. $503 \mathrm{pp}$.

Fastovsky, D. E., Huang, Y., Hsu, J., Martin-McNaughton, J., Sheehan, P. M. \& Weishampel, D. B. 2004, The shape of Mesozoic dinosaur richness. Geology 32, 877-80.
Fiorillo, A. R. 1991. Dental microwear on the teeth of Camarasaurus and Diplodocus: Implications for sauropod paleoecology. In Kielan-Jaworowska, Z., Heintz, N. \& Nakrem, H. A. (eds) Fifth Symposium on Mesozoic Terrestrial Ecosystems and Biota, 23-24. Oslo: University of Oslo.

Fiorillo, A. R. 1995. Enamel microstructure in Diplodocus, Camarasaurus and Brachiosaurus (Dinosauria: Sauropoda) and its lack of influence on resource partitioning by sauropods in the Late Jurassic. In Sun, A. \& Wang, Y. (eds) Sixth Symposium on Mesozoic Terrestrial Ecosystems and Biota, 147-49. Beijing: China Ocean Press.

Fiorillo, A. R. 1997. Tooth wear. In P. J. Currie, P. J. \& Padian, K. (eds) Encyclopedia of Dinosaurs, 743-45. San Diego: Academic Press. 869 pp.

Fiorillo, A. R. 1998. Dental microwear patterns from the sauropod dinosaurs Camarasaurus and Diplodocus: Evidence for resource partitioning in the Late Jurassic of North America. Historical Biology 13, 1-16.

Hendrickx, C., Mateus O. \& Araújo R. 2015. A proposed terminology of theropod teeth (Dinosauria, Saurischia). Journal of Vertebrate Paleontology 35(5), e982797.

Holtz, T. R., Brinkman, D. L. \& Chandler, C. L. 1998. Denticle morphometrics and a possible omnivorous feeding habit for the theropod dinosaur Troodon. Gaia 15, 159-66.

Jacobsen, A. R. 1998. Feeding behaviour of carnivorous dinosaurs as determined by tooth marks on dinosaur bones. Historical Biology 13, 17-26.

Jacobsen, A. R. \& Bromley R. G. 2009. New ichnotaxa based on tooth impressions on dinosaur and whale bones. Geological Quarterly $\mathbf{5 3}$, $373-82$

Lee, J. J.-W., Constantino, P. J., Lucas, P. W. \& Lawn, B. R. 2011. Fracture in teeth a diagnostic for inferring tooth function and diet. Biological Reviews 86, 959-74.

Mallon, J. C. \& Anderson, J. S. 2014. The functional and palaeoecological implications of tooth morphology and wear for the megaherbivorous dinosaurs from the Dinosaur Park Formation (upper Campanian) of Alberta, Canada. PLoSONE 9(6), e98605.

Molnar, R. E. 1998. Mechanical factors in the design of the skull of Tyrannosaurus rex (Osborn, 1905). Gaia 15, 193-218.

Paul, G. P. 1988. Predatory Dinosaurs of the World. New York: Simon \& Schuster. 464 pp

Rowe, K. G., Erickson, G. M., Sawyer, W. G. \& Krick, B. A. 2014. Evolution in surfaces: Interaction of topography with contact pressure during wear of composites including dinosaur dentition. Tribology Letters 54, 249-55.

Rybczynski, N. \&. Vickaryous, M. K. 2001. Evidence of complex jaw movement in the Late Cretaceous ankylosaurid Euoplocephalus tutus (Dinosauria: Thyreophora). In K. Carpenter, K. (ed.) The Armored Dinosaurs, 299-317. Bloomington: Indiana University Press. 512 pp.

Sankey, J. T., Brinkman, D. B., Guenther, M. \& Currie, P. J. 2002. Small theropod and bird teeth from the Judith River Group (late Campanian), Alberta. Journal of Paleontology 76(4), 751-63.

Schubert, B. W. \& Ungar, P. S. 2005. Wear facets and enamel spalling in tyrannosaurid dinosaurs. Acta Palaeontologica Polonica 50 93-99.

Sereno, P. C. 2012. Taxonomy, morphology, masticatory function and phylogeny of heterodontosaurid dinosaurs. ZooKeys, Special Issue 226, 1-225.

Upchurch, P. \& Barrett, P. M. 2000. The evolution of sauropod feeding mechanisms. In Sues, H. D. (ed.) Evolution of Herbivory in Terrestrial Vertebrates: Perspectives from the Fossil Record, 79 122. Cambridge: Cambridge University Press. $268 \mathrm{pp}$

Weishampel, D. B. 1984. Evolution of jaw mechanisms in ornithopod dinosaurs. Advances in Anatomy, Embryology and Cell Biology 87, $1-110$.

Weishampel, D. B. \& Norman, D. B., 1989. The evolution of occlusion and jaw mechanics in Late Paleozoic and Mesozoic herbivores. Geological Society of America, Special Paper 238, 87-100.

Williamson, T. E. \& Brusatte, S. L. 2014. Small theropod teeth from the Late Cretaceous of the San Juan Basin, northwestern New Mexico and their implications for understanding latest Cretaceous dinosaur evolution. PLoSONE 9(4), e93190 (pp 1-23). 
